\title{
Effects of an economic downturn on construction partnering
}

\section{Jason Challender MSc FRICS FHEA FAPM, Peter Farrell MSc PhD FRICS FCIOB, Fred Sherratt PhD MCIOB CBuildE MCABE FHEA}

\section{Introduction}

Despite perceived advantages, collaborative working practices within the construction industry are still relatively rare (RICS, 2005), and appear to have become more so during times of austerity. The RICS Contracts in Use Survey (RICS, 2012) found that partnering contracts during 2010 accounted for only $0.9 \%$ of all contracts by value, compared with $6.6 \%$ in 2004 and $15.6 \%$ in 2007, a trend which could be attributed to the recent UK economic crisis. As a backdrop to this study Fig 1.1 illustrates the effect of such crisis between 2008 and 2012 on UK construction output.

It is perceived by some clients that open and competitive procurement systems, that truly market test prices, are the only way to assure stakeholders of most competitive initial capital cost (Ross, 2011); and in this economic context, 'partnering has not lived up to expectations' (Gadde and Dubois, 2010). This study seeks to explore, the concept of trust during austerity in collaborative working and partnering arrangements. Trust is considered in the literature to be an essential element in successful partnering (Kaluarachi and Jones, 2007). The terms 'partnering' and 'collaborative working' are used interchangeably within this paper, referencing a wider philosophy of trust, fairness and equity, rather than specific details of practice.

\section{Perfection through procurement}

Partnering and collaboration have long been championed as the future of the UK construction industry. Latham (1994) sought to 'Construct the Team' and was heavily critical of traditional procurement and contractual routes, largely due to the lack of collaboration and integration of construction and design stages. He suggested a change in culture and a move to partnering to increase fairness, encourage teamwork and enhance performance through collaborative engagement of clients and design teams with contractors (ibid 1994:50). Egan (1998) saw early establishment of construction teams as an essential aspect of co-operative construction, with contractors able to contribute to management, buildability, health and safety, procurement and supply chain management of projects. It was thought that such early collaboration reduces disputes, reduces tender costs and improves team working practices (ibid 1998:20). 
More recently, the benefits of collaboration have been argued to include an increase in profits brought about by sharing expertise, knowledge, ideas, innovation, best practice, and promoting efficiencies and improvements in decision making (Hansen and Nohria 2004:25). Collaborative working is also suggested to reduce the negative aspects of construction procurement, minimising conflicts and disputes through increased cooperation, and developing relationships built on trust (Larson 1997). Government support for partnering and collaborative thinking was championed by the Strategic Forum for Construction in the 'Accelerating Change' report (Egan 2002). Projects that had applied the principles of both Latham and Egan in the use of collaborative procurement methods were found to achieve significant improvements in client satisfaction, cost predictability, safety, and time predictability.

Yet, partnering and collaborative procurement has also attracted its critics. The RICS (2005:2) argued that successful experiences in collaborative procurement '... are largely anecdotal and focus on the experiences of exemplar organisations.' A similar argument is presented by Morgan (2009:9), formerly procurement director at BAA, who concludes that with major capital projects, procurement routes that promote alliances and partnerships are not always appropriate, being vulnerable to abuse given the scale of the commercial interests involved.

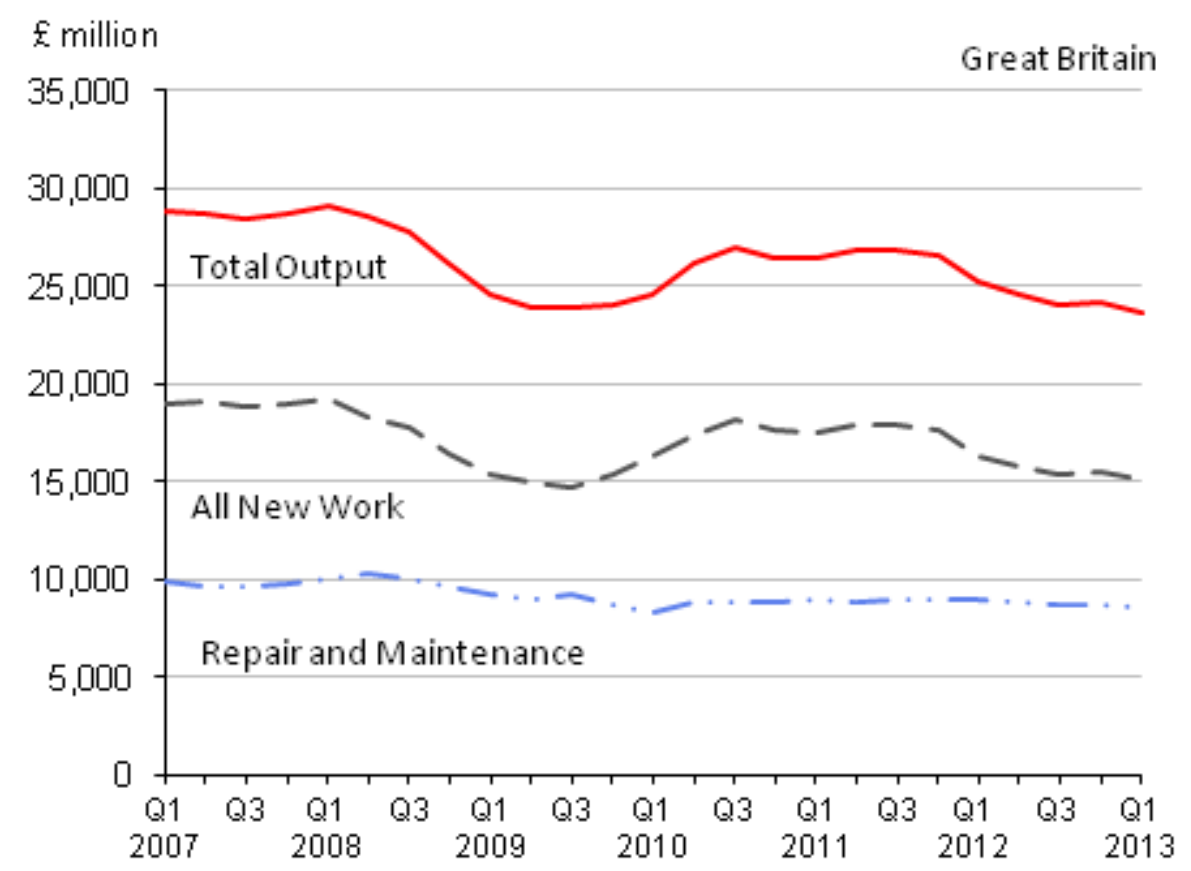

http://www.ons.gov.uk/ons/resources/scttotconsmar13_tcm77-306819.png 


\section{Trust as a collaborative necessity}

There is a view that when companies enter into highly complex, uncertain and potentially risky projects as relative strangers, it is not surprising that frequent conflicts and disputes arise in traditional procurement systems (Chan et al., 2004). Partnering and collaborative approaches seek to avoid conflicts and disputes by increasing levels of co-operation and developing organisational relationships built on trust (Larsen, 1997). It is however recognised that such approaches do not provide guaranteed mechanisms for the development of trust (Bresnen and Marshall, 2000:230), and the complexities of developing trust in a single combined operational entity through collaboration are vast. Trust is likely to be dependent on a number of factors, including social interaction, power, identities and expectations. In project teams, individuals may inherently have varying propensities to trust and be trusted (Walker 2009:158).

The degree of trust between key members of teams has been identified as a critical factor in shaping relationships between all project team participants, as well as a key influence in project outcomes (Walker 2009). Gadde and Dubois (2010:256) referred to the concept of 'the relationship atmosphere', determined by the 'balance of collaboration', encompassing constructive elements such as commitment and trust, as well as negative elements such as power and conflict. Kaluarachi and Jones (2007:1053) also found that communication, trust, change in mindset, and commitment of participants were all major factors in developing successful and innovative partnering agreements.

The former chief construction advisor to Government, Morrell (2011), argues that greater coordination is needed in the preparation of project documentation to encourage partnering, buildability, standardisation, prefabrication and collaborative working in the pursuit of value for money. Yet in order to enable the communication and sharing of knowledge necessary for fullyintegrated practice, trust between supply chain members, from clients to the smallest SMEs, is a fundamental requirement. Through development of their propensity to trust theory, Briscoe and Dainty (2005:230) identified a potential lack of desire amongst specialist supply chain partners to trust their more powerful main contractor partners. They report that specialists have negative experiences in sharing information and prompt payment initiatives, leading to organisational mistrust. The placing of risk where it can be controlled best has emerged as a key contributor to collaboration. This is especially the case as Black et al. (2000) and Strahorn et al. (2014) considered shared risk as a major generator of trust. They concurred that risks should be identified by all parties and which organisations and individuals are best placed to manage and take responsibility for these. They justified this approach on the basis that one cannot simply transfer risk without someone ultimately paying for it. Risk workshops could also overcome any perceptions that risks may have become unfairly allocated which Walker (2009) regarded as a major barrier for trust development. 
The quality of collaboration can be reinforced or weakened, depending on the behaviour, approaches and attitudes of both organisations and individual participants (Coulson-Thomas, 2005:179). There is heavy reliance on relationships within teams, but in practice the time needed to nurture these relationships, is often lacking in construction management procurement systems (Walker 2009:140). The literature suggests that trust is a vital factor in the development of successful partnering and collaborating working practices.

\section{Potential problems for collaborative procurement: trust in times of austerity}

The project-based nature of much construction work can be seen as a fundamental barrier to the development of trust in practice, where relationships are perceived to be short term, and true collaborative working practices struggle to emerge (Walker, 2009). Furthermore, a perceived 'loss of control' has also been identified as a barrier to collaborative working. Perhaps these concerns over control would not have emerged if trust had been more prevalent. This is justified on the premise that trust is 'the most important risk-minimisation strategy' (Ceric, 2014) and 'very fragile, but once developed it can outshine all the other strategies in terms of project controls and contracts' (Ceric, 2012). There is a concern that sharing of knowledge results in loss of knowledge, adding to a more general uncertainty (Thurairajah et al., 2006:7). Such managerial uncertainty is unlikely to encourage new collaborative working arrangements during a time of economic doubt; austere times suggest a return to familiar and trusted traditional procurement systems.

Reliance on the known and controllable has previously been identified within industry, as a symptom of a 'negative culture', sceptical and suspicious of new initiatives. It has been argued that these old behavioural aspects, cultures and attitudes are so deeply embedded in the construction sector that they are proving difficult to change (Thurairajah et al., 2006:7). For partnering approaches to be more attractive to clients, they must seek to address problems of cultural indifference, old stereotypes and adversarial views of team members alongside new ways of working being established (Liu et al., 2004). Yet it is unlikely that an economic downturn will provide a suitable context for such paradigm shifts in practice. Indeed, the RICS (2012) have suggested that partnering is not compatible with an economic climate of recession; most competitive capital cost becomes politically more important than long term best value measures. Research studies have found some clients commonly fixate on obtaining most competitive bid price rather than best value (Beach et al., 2005). This may become more profound in austerity where a 'bullish' private sector employer may wish to take advantage of the depressed economy to achieve cheaper construction costs, often at the expense of the supply chain. Some would argue that such practices serve to bully and intimidate contractors into accepting unfair returns under the banner of collaboration (Challender et al., 2013). 
When partnering is used, there may on occasion be an abuse of power by clients towards main contractors, or main contractors towards their supply chain, to 'squeeze ... too hard' (National Audit Office, 2001:62). In times of austerity the desire to squeeze can become a necessity, challenging the benefits of the partnering relationship. Indeed, one of the most prolific barriers to increased collaboration could be psychological; clients who seek to prolong strategies associated with market leverage and power, achieve most competitive price, rather than best value, and increase supply chain competition (RICS, 2005:2). This view could also apply to the relationships between main contractors and subcontractors, where the 'buyers' dictate to the 'sellers' the terms of their employment and what is required of them (Mathews et al., 2003:167).

In the sense that collaboration is ideally for the long term, and over multiple projects, economic conditions may dictate that clients cannot commit too far ahead. The constraints and challenges for many clients, make partnering a problematic aspiration, and they are forced to limit themselves to mere single project awards (Mason, 2006:5).

\section{Methodology}

In order to further explore collaboration and partnering, within a contemporary period of economic austerity, and also examine the role of trust within this context, a qualitative study was undertaken (Flick, 2009). This approach enabled the exploration of key themes, understandings and attitudes of those who work within this environment on a daily basis.

Semi-structured in-depth interviews (Gillham, 2005) were held with eight construction professionals from different construction industry disciplines; an architect, quantity surveyor, client project manager, main contractor, subcontractor, property lawyer, mechanical and electrical engineer and a structural engineer. A purposive sampling strategy was employed, selecting professionals with experience in partnering and collaborative working practices. However, beyond these two criteria, the sample was one of convenience. Whilst the small sample size does not allow for generalisation, it does provide insight into the perceptions of those working within the construction industry during the economic crisis, and their understanding of trust in collaborative working. Consultations were carried out to plan and formulate the format and structure for the interviews. A 'pilot' interview was conducted to obtain feedback on the data collection tool, and tease out any difficulties with the way it was designed and administered.

The interviews were undertaken in a period of austerity; late 2012 to 2013 . They were digitally recorded, transcribed verbatim and subsequently coded and sorted (Silverman, 2001; Langdridge, 2005). Examples of the main qualitative codes included informal engagement, closer interaction and good team working whereas examples of the main themes included 
factors that instil trust and potential barriers to collaborative working. As recommended by Taylor and Bogdan (1998), the raw data was summarised in tables; codes were listed, themes developed, content analysis data presented, key literature sources identified, data consistencies and inconsistencies noted and propositions made. The tables became a plan to develop a narrative to construct a contemporary picture of partnering and collaborative working in austere times. Table 5.1 contains the main first level observations and themes. Due to constraints of space in this paper, the narrative has been interwoven with its discussion, to contextualise the findings of the study.

1.1 Table 5.1 Qualitative themes

\begin{tabular}{|c|c|}
\hline Theme/group title & First level observation \\
\hline \multirow[t]{6}{*}{ Importance and reliance on trust } & Problem solving ethos \\
\hline & Improvements to project performance \\
\hline & Closer interaction \\
\hline & Cooperation between individuals \\
\hline & Informal engagement \\
\hline & Alignment of organisational strategies \\
\hline \multirow[t]{6}{*}{ Factors that instil trust } & Previous relationships/dealings \\
\hline & Good team working \\
\hline & Openness and transparency \\
\hline & Working to common goals \\
\hline & Sharing of information \\
\hline & Improvements to project management \\
\hline \multirow{3}{*}{$\begin{array}{l}\text { Importance and influence of hard and soft } \\
\text { factors }\end{array}$} & Competence of project team \\
\hline & Willingness to collaborate \\
\hline & Motivation of project team \\
\hline \multirow[t]{6}{*}{ Best practice } & Competence of project team \\
\hline & Willingness to collaborate \\
\hline & Motivation of project team \\
\hline & Education and training \\
\hline & Supply chain integration \\
\hline & Organisational commitment \\
\hline \multirow[t]{7}{*}{ Potential barriers } & Availability of resources \\
\hline & Sharing of information \\
\hline & Management resources and expertise \\
\hline & $\begin{array}{l}\text { Differentiation between organisations and } \\
\text { individuals }\end{array}$ \\
\hline & Governance and legislation \\
\hline & Contractual matters \\
\hline & Adversarial attitudes and behaviour \\
\hline Improvement measures & Change in culture \\
\hline
\end{tabular}




\begin{tabular}{|l|l|}
\hline & Improvements to training and education \\
\cline { 2 - 2 } & Fairness and benefit sharing \\
\hline
\end{tabular}

\section{Research findings and discussion}

\subsection{Challenging the Philosophy of Collaboration}

Collaboration is based on trust, equity and fairness. A shared ethos between partners is essential for collaborative success, and all these philosophies should be embedded in aligned organisational strategies (Thurairajah et al., 2006; Bresnen and Marshall, 2000). However, whilst supported theoretically, rarely is there realisation in practice. Participants reported that partnering has been tainted by inequitable working arrangements which give little or no benefits to partnered organisations.

The disparity of power between clients and other organisations has allowed the former to take advantage of collaborative arrangements to serve their own organisational needs; arrangements for sharing have become significantly one-sided. Some organisations take advantage of austerity to bully partners further down the supply chain; they use the power derived from scarcity of work elsewhere in the economy to use a 'take it or leave it approach'. The abuse of power to secure organisational gains at the expense of others, appears to have become too much to resist. A shift in philosophy during an operational partnering framework renders organisations highly vulnerable to exploitation as they are virtually held to ransom; to accept revised or reduced terms, or be cast back into a cut-throat market place. Such exploitation through partnering frameworks increases the risk of this procurement option, reducing its attractiveness and contributing to a reduction in willing partners.

Not all of the participants advocated trust as a critical factor for generating successful partnering outcomes. One participant explained that they regarded '... construction as a business and whilst trusting collaborative working relationships are desirable, they will not guarantee profit margins and survival in a very difficult and competitive economic climate.' It was explained that partnering could disadvantage contractors in some cases, especially when dealing with more powerful clients, preventing them from receiving fair and reasonable commercial returns from projects. Furthermore, cases were described where clients had made significant changes but still expected these to be absorbed into the original price in '...the spirit of the collaborative arrangement'. They warned that unfair relationships will make one partner feel that the other is taking advantage which could undermine trust. 
An alternative position, however, emanated from the client project manager's perspective who reported that:

'The main problem with integrating collaboration and trust into the construction industry is when people have their own agendas and ultimately the agenda for the contractor is to make money. Whilst partnering and collaborative working can work in practice the contractor can see it as an opportunity to increase profits. This opportunism, however, will always be there. The problem with the adversarial attitudes from the contractor is that is something that develops over years and it is almost engrained. Partnering is a relatively new way of doing things and is difficult for a leopard to change its spots. Cultural change could be therefore difficult in this regard.'

The architect participant explained that to overcome these barriers and difficulties to implementation and success of partnering it is essential to ensure that the contractor earns a reasonable profit level to remove the need for opportunistic behaviour. In this way '.. you would take away the contractor's need for adopting an opportunistic attitude to make more money.'

\subsection{Austerity in Practice}

Although collaborative working potentially creates a less antagonistic and stressful working environment, facilitating better individual performance, and subsequently better team and project performance, it is still met with scepticism. Suspicion of realisable benefits as claimed emerge; for example, cost savings for clients from collaborative working are perceived to have become exaggerated over time. Further, partners lower down the supply chain provide anecdotal evidence of where they have suffered financially. Such 'ghost stories' reinforce fears and anxieties over risks within the industry, and promote a reluctance to move away from traditional working methods.

Indeed, a continued reliance on experience and the familiar appears to be providing comfort; competitive tendering and traditional procurement have been the norm for many years (Mason, 2006). In periods of insecurity and uncertainty, it may simply not be the right time to implement new practices that are relatively untested. This fear of the unknown can also be related to the personal uncertainty felt by construction professionals, unwilling to take risks. Job security and 'playing safe' in times of austerity may be influencing procurement practices.

The perceived lack of financial benefits or incentives to move towards collaborative practices appears to have grown in influence. A short term focus either remains, or has returned to those who embarked on collaborative strategies, favouring contract award through most competitive bid price, rather than exploring other criteria which may enable the development of long term 
collaborative relationships. Initial capital tender costs are seen by some clients as most important; irrespective of the fact that there are many authoritative claims that low bid costs lead to higher final accounts and poor life cycle value. Indeed, as suggested by the RICS (2012) and Morgan (2009), short term commercial interests override the principles and perceived benefits of partnering. As the economic climate puts financial strain on many construction organisations, the management of cash-flow and financial accounting becomes ever more focused.

Examples were reported where senior client executives of non-property related backgrounds had insisted on most competitive price tendering as a misguided approach to achieving best value. These individuals were described as being openly dismissive of any alternative procurement types such as partnering in the past, favouring more competitive tendering routes. Their justification for this reversion to 'tried and tested' procurement arrangements was reportedly based on partnering not fully meeting audit and corporate governance requirements for tendering and contract procurement. This would support the view from Ross (2011) that competitive tendering and traditional procurement routes are frequently regarded as ' $\ldots$ the only way to assure stakeholders of most competitive initial capital cost.' This could reflect the inability to demonstrate the financial benefits of collaborative approaches. Nevertheless, participants felt that this dilemma for partnering did represent a misguided and informed perception which is clearly at odds with government recommendations from Constructing Excellence (2015) and HM Government (2013). The directives from these authoritative government sources clearly recommend partnering as a robust form of public sector procurement. It does however demonstrate a distinctly worrying paradox for partnering by non-construction and arguably 'noninformed' senior individuals within client organisations. Furthermore this could present a barrier for future collaborative working and may explain the recent downward trend for partnering contracts in the UK construction industry (RICS, 2012).

Other work practices were also felt to have been affected by austerity. The potential for clients to provide a continuous supply of work (Mason 2006) has become more problematic, again minimising the potential implementation of partnering in practice. Resources within organisations have become stymied; investment in CPD, training programmes and systems designed for integration with other partnering organisations has significantly reduced, restricting developments towards more collaborative processes. This has been felt most in the context of Building Information Modelling (BIM), which requires investment in technology and participation in new systems to support collaborative project teams.

For collaborative practices to succeed, a cultural shift is required (Thurairajah et al., 2006), and BIM has been put forward as the necessary catalyst. Yet embracing cultural change and engaging in further training, investment and CPD is presently not high on the agenda. Organisations, and the individuals who work within them, are facing an uncertain future. 
Industry may not feel the time is right to embark on new initiatives and methods of working practice whilst insecurity looms large.

\subsection{Trust within the Austere Context}

Trust is considered vital for the integration of teams and individuals in the development of collaborative working practices, as suggested by the literature (Latham, 1994; Egan, 1998; Larson, 1997). A 'culture' of trust allows projects to move forward effectively, and creates an environment where problems can be shared and therefore solved more easily. Where trust is lost, working relationships can become untenable. The client participant opined that '.. . trust is not something that can be engineered through contractual conditions, nor through procurement routes alone, but needs to be developed, built up and earned over time'. Furthermore they advocated that '... where trust is lost this can make working relationships untenable and situations could arise where this leads to a "downward cycle of trust" which supports the theory of Thurairajah (2006, pp.1-8). They conceded, however, that trust is not something that can be engineered instantaneously through contractual and procurement routes alone but conversely requires '...to be built and earned over time'. Where trust is developed in this way they reported that working relationships become more reliable and consistent between parties. This provides the conditions where each party can rely more on the other for getting what they expect from partnering

The developmental nature of this process aligns with the long term vision of partnering and a procurement framework approach to construction, yet it is now challenged by austerity. The return to short term contracts and the constant quest for most competitive initial bid price inhibits the development of trust between organisations. However, where long term organisational collaboration is a potential future work-stream, the development of trust within such relationships becomes 'incentivised' and consequently active in practice. Strategic, rather than project partnering is felt to be more desirable, especially on a cluster of many projects of short duration. It is therefore suggested that trust can be generated within encouraging contexts. Potential long-term work in times of austerity needs to promote the development of personal relationships and support collaborative working.

The importance of trust was also found to be influenced by organisational position within the wider project team. Within client-design team relationships, trust was considered to be vital and fundamental to project success; however in client-contractor relationships this was less important as these roles are considered to be diametrically opposite. A possible explanation for this could be that clients employ consultants to represent them whereas clients employ contractors to undertake a distinct tangible piece of work under prescriptive and well defined contractual conditions. One participant went as far as opining that they regarded the 
consultants' roles '.. as an extension of the client'. Also contractors' and clients' interests are still regarded by some in industry as being diametrically at odds with each other. Perhaps this explains why Pinto et al. (2009) opined that behaviours and factors which may encourage trust for clients may not be the same for contractors and vice versa.

Whilst partnerships and collaborative working relationships are desirable, they do not guarantee profit or even survival. Abuse of trust, depending on position within the project hierarchy can lead to abuse of practice. Examples were given by contracting and subcontracting participants that client and design team changes are expected to be absorbed in budgets in 'the spirit of collaborative arrangements'. This is another perspective to be considered in the challenges of partnering and collaborative working.

One individual was critical of the development and employment of trust within the wider organisational context. Either positively or negatively, communications, commitment, confidence, teamwork and personalities of individual team members were all found to be important elements in the building of trust in organisational operations, as suggested by Walker (2009); although the strength of trust is more dependent on individual personal relationships, developed from mutual respect, rather than simply 'good' working relationships. Austerity has further influenced personal relationships, as individuals become more focused on their own individual situations, rather than wider organisational concerns, reflecting growing uncertainty (Thurairajah et al., 2006). Trust generated from previous relationships and dealings and between individuals at senior levels is regarded as critical in the cascading of trust throughout organisations, and between those currently operating partnering arrangements. An integrated project team needs to communicate well and operate within an environment of trust, leading to 'an upward cycle of trust' (Cheung et al., 2003). Some participants opined that competency, attitudes and behaviours of project team individuals and how they relate to each other are the main factors that will determine the levels of trust generation on projects. Das and Teng (1998) referred to this as 'organisational blending'. For this reason one practitioner explained that new recruits to their organisation are given time to absorb their collaborative values and culture. The importance of this was explained from the perspective that '... it has taken them many years to build the trust of clients but could take moments to lose if the wrong individuals are employed'.

At an operational level, 'human' factors such as integrity, honesty, consistency, reliability and competency are regarded as important in facilitating good collaborative working. Such factors are suggested by Thuraujarah et al. (2006) and Cheung et al. (2001) as vital for the greater integration of project teams, providing the right environment for partnering to succeed. Yet, hard factors are also put forward as crucial in the partnering process: experience, technical ability, education and competence of individuals, management systems, resources, and commitment of 
the organisations. For partnering to succeed, in the contemporary climate, the development of trust needs all the help it can get.

\subsection{Effects of austerity on collaborative procurement}

The study revealed for the most part that although trusting collaborative working relationships are desirable, they will not guarantee profit margins and survival in a very difficult and competitive economic climate. Partnering could disadvantage lower levels of the supply chain, especially when dealing with more powerful partners. In certain circumstances partnering arrangements allow clients to 'bully' contractors into accepting unfair returns under the banner of collaborative arrangements. Members of the supply chain at higher levels may lead their partners to financial loss on some projects. These situations, if not managed correctly, can lead to a 'downward cycle of trust', weakening relationships and leading to further deterioration of trust (Thurairajah 2006, pp.1-8). Perhaps it is Poppo and Zenger's model (as cited in Lann et al., 2011, pp.97-99) which advocates that trust and control should work in tandem and reinforce one another to address risks that provides a more balanced approach. In considering this difficult dilemma on the balance of trust and control one should consider that there are specific forms of risk that appear to have become synonymous with collaborative working practices. One example of this comes from Langfield-Smith (2008), in the form of 'relational risk', which is argued to be unique to partnering arrangements. It relates to the outcomes where partners do not cooperate and will be high where there is a perceived high degree of behavioural uncertainty. Perhaps trust may be regarded as the means by which such potential aforementioned risks, possibly associated with opportunistic behaviour may be reduced.

Reinforcing the views of Mason (2006) the study confirms that competitive tendering and traditional procurement have been the norm for many years. As such, in times of austerity when there is much insecurity and uncertainty, it may not simply be the right time to be engaging in new practices that are relatively speaking still not properly tested. There is a fear of the unknown and some construction professionals are not prepared to take the associated risks. Job security and 'playing safe' in times of austerity may override the adoption of collaborative working practices.

The research findings support the view of Beach et al. (2005), Oyegoke et al. (2009) and Wolstenholme (2009) in that professional development, education and training, operational and cultural change and commitment to continual improvement would be required if partnering, in austere times especially, is going to succeed in the future. Along with the recommendation of Morrell (2011) this could also bring cost savings to the industry in terms of buildability, standardisation, prefabrication and value engineering. Organisations are still looking to the short term and favouring selection of the most competitive tenders rather than looking at other criteria which may promote long term collaborative benefits. 
The study also found that the current economic climate is putting a financial strain on many construction organisations and this is particularly the case with smaller consultants, main contractors, and subcontractors. Findings indicate that this could be adversely affecting the deployment of resources and affordability of initiatives linked to embracing partnering and collaborative working philosophies. The study also finds that smaller organisations may not be investing in CPD, training programmes and systems designed to integrate with other partnering organisations. This argument is consistent with the findings of Dainty et al. (2001) which suggests that there is sometimes reluctance from organisations and individuals to expend time and resources in developing collaborative relationships, especially when affordability is an issue.

\section{Conclusions}

Owing to the interview base being relatively small, and therein regarded as a sample of convenience, these conclusions are presented as opinions that may not be inferred to be present amongst all practitioners.

An economic climate of austerity appears to have significantly influenced the trust element in collaborative procurement. Collaboration appears to have been undermined from a number of positions. From the perspective of individuals, job security has become paramount, influencing choices made within work practices, and leading to reluctance to take risks. From an organisational perspective, collaborative working is no longer an attractive prospect in uncertain economic times. Long-stated, sceptical arguments against partnering have gained credibility as tales of abuse in organisational relationships and the trust on which they are based, have emerged. A return to traditional competitive practices has been driven by perceptions that partnering is expensive; there is a need to assure most competitive price at bid stage.

Austerity appears to be incentivising some to deploy market leverage to achieve most competitive tenders. Long term best value is less important. This not only hinders, but potentially abuses the development of collaborative working. Clients are trying to 'squeeze' contractors, and, in response, contractors are seeking profit through commercial claims and variations, and by squeezing lower levels in the supply chain.

A return to traditional practices offers psychological security and appears to focus on what matters most in austere times; money. Yet this is a very short term perspective, and a lack of investment in collaborative training and innovations such as BIM could result in missing the industry's next major technological shift in practice.

Collaborative procurement may be perceived as a risky alternative to traditional competitive tendering, and logically, it unlikely to be launched by clients as a new initiative in austere times. 
Given that austerity is forecast to last by some commentators for a decade or more, and many clients who have previously practiced collaboration are reverting back to market testing through open and competitive traditional bidding, it is possible that the market share of collaborative procurement systems, based on trust, will fall further into decline. However, BIM may be the initiative that 'keeps the collaborative procurement flag flying'. More research is recommended to explore the approach to collaboration in times of austerity as was experienced in the UK between 2008 and 2012. Such studies could examine the emergent issues over a longer time period, when the consequences of the shift back to traditional procurement processes has begun to impact on the success of projects. It could provide a further historical perspective with lessons for the future.

\section{Acknowledgments}

The authors greatly appreciate the professional practitioners whose interviews provided the basis for the qualitative research and would like to thank them for their contributions accordingly.

\section{References}

Beach, R, Webster, M and Campbell, K M (2005) An evaluation of partnership development in the construction industry. International Journal of Project Management. 23(8), 611-621.

Black, C, Akintoye, A and Fitzgerald, E (2000) An analysis of success factors and benefits of partnering in construction. International Journal of Project Management, 18(2000): 423434.

Bresnen, M and Marshall, N (2000) Partnering in construction: a critical review of issues, problems and dilemmas. Construction Management and Economics. 18(2), 229-237.

Briscoe, G and Dainty, A (2005). Construction supply chain integration:an elusive goal? Supply Chain Management: An International Journal, 10(4): 319-326.

Ceric, A (2012) Strategies for minimising information asymmetries in construction projects: project managers' perceptions. Journal of Business Economics and Management,13(2): 23-33.

Ceric, A (2014) Communication risk and trust in construction projects: A framework for interdisciplinary research In: Raiden, A B and Aboagye-Nimo, E (Eds) Procs 30th Annual 
ARCOM Conference, 1-3 September 2014, Portsmouth, UK, Association of Researchers in Construction Management, 835-844.

Challender, J, Farrell, P, and Sherratt, F (2013) Collaborative procurement: an exploration of practice and trust in times of austerity In: Smith, SD and Ahiaga-Dagbui, DD (Eds) Procs $2^{\text {th }}$ Annual ARCOM Conference, 2-4 September 2013, Reading, UK, Association of Researchers in Construction Management, 827-836.

Chan A P C, Chan D W M, Chiang Y, Tang B, Chan E H W and Ho K S K (2004) Exploring critical success factors for partnering in construction projects. Journal of Construction Engineering and Management. 130(2), 188-189.

Cheung, S O, Lam, T I, Leung, M Y and Wan, Y W (2001) An analytical hierarchy process based procurement selection method. Construction Management and Economics. 19(4), 427-437.

Cheung, S O, Thomas, S T, Wonga, S P and Suena, C H (2003). Behavioural aspects in construction partnering. International Journal of Project Management. 21(5), 333-343.

Constructing Excellence (2015) What is a Framework? Constructing Excellence, London, UK. see http://www.constructingexcellence.org.uk/tools/frameworkingtoolkit/what-is-aframework/ [18 th June 2015].

Coulson-Thomas, C (2005) Encouraging partnering and collaboration. Industrial and Commercial Training. 37(4), 179-184.

Dainty, A, Briscoe, G and Millet, J (2001) Subcontractor perspectives on supply chain alliances. Construction Management and Economics, 19, 841-848

Das, T K and Teng, B S (1998) Between trust and control: developing confidence in partner cooperation in alliances. The Academy of Management Review, 23(3): 491-512.

Egan, J (1998) The report of the construction task force. Rethinking Construction, London: DETR.TSO.

Egan, J (2002) Accelerating Change. London: Rethinking Construction.

Flick, U (2009) An Introduction to Qualitative Research. 4ed. London: Sage Publications Limited. 
Gadde, L E and Dubois, A (2010) Partnering in the construction industry: problems and opportunities. Journal of Purchasing and Supply Management. 16, 254-263.

Gillham, B (2005) Research Interviewing: the Range of Techniques. Maidenhead: Open University Press.

Hansen, M T and Nohria N (2004) How to build a collaborative advantage. MIT Sloan Management Review, 46(1), 22-30.

H M Government (2013) Construction 2025. Industry Strategy: Government and Industry in Partnership. London: HM Government. 23-25, 61-71.

Kaluarachchi, D Y and Jones, K (2007) Monitoring of a strategic partnering process: the amphion experience. Construction Management and Economics. 25(10), 1053-1061.

Langdridge, D (2005) Research Methods and Data Analysis in Psychology. Pearson Education: Harlow.

Larson, E (1997) Partnering on construction projects: a study of the relationship between partnering activities and project success. IEEE Transactions on Engineering Management. 44(2), 188-195.

Latham, M (1994) Constructing the Team. London: The Stationery Office.

Liu, A, Fellows R and Nag, J (2004). Surveyors' perspectives on ethics in organisational culture. Engineering, Construction and Architectural Management. 11(6), 438-449.

Mason, J (2006) The views and experiences of specialist contractors on partnering. Proceedings of the Annual Research Conference of the Royal Institution of Chartered Surveyors 7-8 September, University College London.

Mathews, J, Kumaraswamy, M and Humphreys, P (2003) Pre-construction project partnering: from adversarial to collaborative relationships. Supply Chain Management, 8(2), 16678.

Morgan, S. (2009) The right kind of bribe. Building Magazine, 9th October 2009.

Morrell, S (2011) Major Strategic Priorities and Opportunities for Construction. Build Offsite Available at http://bit.ly/120dKeL [17 January 2013] 
National Audit Office (2001). Modernising Construction. Report by the Controller and Auditor General HC 87 Session 2000-2001. London: The Stationary Office.

Office of National Statistics (2013). UK construction output 2007-2013. See http://www.ons.gov.uk/ons/resources/scttoconsmar13 tcm77-306819.png [17th November, 2015).

Oyegoke, A S, Dickinson, M, Malik, M A, McDermott, P and Rowlinson, S (2009) Managing projects in construction project procurement routes: an in-depth critique. International Journal of Business. 2 (3), 338-354.

Pinto, J K, Slevin, D P and English, B (2009) Trust in projects: an empirical assessment of owner/contractor relationships. International Journal of Project Management, 27(6): 638648.

Ross, A (2011) Supply chain management in an uncertain economic climate: a UK perspective. Construction Innovation, 11(1), 5-13.

RICS (Royal Institution of Chartered Surveyors) (2005) An exploration of partnering practice in the relationships between clients and main contractors. Findings in Built and Rural Environments. RICS Research, London, UK, 2-3.

RICS (2012) Contracts in Use. A Survey of Building Contracts in Use during 2010. London: Royal Institution of Chartered Surveyors Publications.

Silverman, D (2001) Interpreting Qualitative Data: Methods for Analysing Talk, Text and Interaction. 2ed. London: Sage Publications Limited.

Strahorn, S, Gajendran, T and Brewer, G (2014) Experiences of trust in construction project management: The influence of procurement mechanisms In: Raiden, A B and AboagyeNimo, E (Eds) Procs 30th Annual ARCOM Conference, 1-3 September 2014, Portsmouth, UK, Association of Researchers in Construction Management, 463-472.

Taylor, S and Bogdan, R (1998) Introduction to Qualitative Data Research Methods. $3^{\text {rd }}$ Edition. New York. John Wiley

Thurairajah, N, Haigh, R and Amaratunga, R D G (2006) Cultural transformation in construction partnering projects. Proceedings of the Annual Research Conference of the Royal Institution of Chartered Surveyors 7-8 September. University College London. 
Walker, A (2009) Project Management in Construction. Oxford: Blackwell Publishing Ltd.

Wolstenholme, A (2009) Never Waste a Good Crisis; A Review of Progress Since Rethinking Construction and Thought for Our Future. London: Constructing Excellence in the Built Environment. See http: //dspace.lboro.ac.uk/dsspace-

jspui/bitstream/2134/6040/1/Wolstenholme\%20Report\%200ct\%200ct\%202010.pdf. (accessed 13/01/14). 